\title{
Reflections of Positive Experiences in Midwifery and Nursing of Maternal-Newborn Education in Thailand: Lessons Learned from Naresuan University
}

PRATUMA RITHPHO, PhD, MNS, RN https://orcid.org/0000-0003-3034-355X
PANTIPA BUAKHAI, MNS, RN

https://orcid.org/0000-0002-2845-7331

Naresuan University, Phitsanulok province, Thailand

Corresponding author's email: rpratuma@yahoo.com

\section{Abstract}

The success of maternal and child health practices emphasizes on health policies, building effective partnerships, advocating for investments in maternal and newborn health, and coordinating research that focuses on improving maternal health in pregnancy and during and after childbirth. In these situations, nurses and midwives are the key resources who comprise the greater part of the healthcare workforce. Nurses and midwives make substantial contributions to healthcare delivery systems especially in primary care, acute care, and community care setting. Thailand has an excellent production of nurses since they can perform duties as a nurse and as a midwife. This is what we think nurses from other countries should apply in their countries to improve health services. We can also show that our country has a low gender gap in employment not just in nursing. This paper would like to present the lessons learned from Thailand Nursing Education purposed in midwifery, maternal and newborn nursing at Naresuan University. Specifically, the purpose of this article was to discuss the midwife and maternal and newborn education standards in Thailand and describe the experiences using reflective knowledge in order to inform current and future midwifery and maternal and newborn nursing practices in Thailand.

Keywords: Maternal and newborn education, midwifery education, positive consequences, Thailand 


\section{Introduction}

resently, more than 300,000 women around the world die during pregnancy and childbirth, some 3 million babies do not survive the first month of life, and another two and a half million babies are stillborn. Most of them could have been saved by the care of well-trained midwives within the framework of strong health systems (United Nations Population Fund [UNFPD], 2017). In Thailand, according to the RNs competencies, the modern midwife and nurse can now assist women who may have died in the past during pregnancy and childbirth. High percentages of laboring women $(97 \%)$ are attended by skilled health personnel, much higher than the regional average $(49 \%)$. In addition, Thailand is a successful country as presented by the MMR rate as compared with other countries in ASEAN and the rest of the world. Thailand has the lowest MMR rate in ASEAN which makes it a good destination for nurses from other countries to learn how Thai nurses manage this situation. We would like Thailand to be the leader in ASEAN in tackling MMR since the cases are consistently low as compared to other countries. They can learn from our educational system as well as from the health care delivery system by making nurses equipped with midwifery skills in order to provide the best services to pregnant women and their families.

Nursing was the first education-based occupational field for women in Thailand which started more than 100 years beginning with hospital bedside care (Muecke \& Srisuphan, 1989). In 1896 the first nursing school in Thailand, School of Medicine-Midwifery and Female Nurses, was opened and developed by Queen Sripatcharintra. In 1925-1936, when Prince Mahidol returned to Thailand after studying as a physician in the USA, the Rockefeller Foundation collaborated with the Ministry of Public Health - by sending nurses to study abroad and for USA nurses to consult in Thailand. In 1970, the Ministry of University Affairs in Thailand confirmed that university-educated nurses are prepared to function as teachers, planners, implementers, and evaluators in public health. Then, Thai universities began to see the establishment of nursing in academia as an independent professional discipline in 1971 (Brandt et al., (n.d).

The midwifery education in Thailand is absolutely different from developed countries such as Canada, the United State of America, United Kingdom, and Australia. They are separate from nursing at undergraduate programs (Bourgeault, Neiterman \& LeBrun, 2011). Our midwifery program is also different from other developing countries such as in Indonesia, Laos, and the Philippines in which they separated the midwifery program from nursing. This paper would like to describe maternal and newborn education standards by reflecting on experiences in order to inform current and future midwifery and maternal and newborn nursing in Thailand. Our neighboring ASEAN countries could apply the experiences they got from Thailand to their services in their countries. This paper will also encourage them to open their minds to apply this information in order to get opportunities in the future. They also learn from their experiences in other countries and by meeting other people. 


\section{Successful Women's Health Issue in Thailand}

Since 2002, Thailand has been successful in implementing universal health coverage for its people. This program presented social protection and equity from birth to end of life care. The scheme is financed through taxation in such a way that those on higher incomes pay more than those on lower incomes. Ambulatory and hospital care are available to the poor through a geographically widespread network of district-level government health facilities (Prakongsai, Tangcharoensathien \& Limwattananon, 2008).

According to the World Health Organization (WHO), Maternal and Child Health (MCH) indicators were used as measures of health outcomes and coverage of health care interventions. The coverage of maternal health indicators was family planning, prenatal care and delivery by a skilled health worker and delivery in a health facility, and postpartum care. Child health indicators were improving the quality of services such as low birth weight, child malnourishment, child illnesses, and basic vaccinations such as bacille Calmette-Guérin (BCG) vaccine, vaccine against measles, mumps and rubella (MMR); three doses of oral polio vaccine (OPV) and vaccine against diphtheria, pertussis (whooping cough) and tetanus (DPT); and one dose of hepatitis $B$ vaccine.

Among 30 low and middle-income countries, Thailand has been one of the most effective countries in reducing mortality in children under five years old (Rohde et al., 2008). For example, the mortality rate fell from 58 in 1980 to 30 in 1990, and to 23 in 2000 per 1000 live births (Hill, Vapattanawong, Prasartkul, Porapakkham, Lim, \& Lopez, 2007). The improvement in child survival has been accompanied by a remarkably small disparity between the rich and the poor (Vapattanawong et al., 2007).

When comparing updated MMR data among ASEAN countries as shown in Table 1, Thailand has done the wonderful intervention to reduce MMR in this country impressively.

Table 1. Maternal mortality rate (deaths/100,000 live births)

\begin{tabular}{ccc}
\hline Country & $\mathbf{2 0 1 0}$ & $\mathbf{2 0 1 5}$ \\
\hline Laos & $\mathbf{4 7 0}$ & 197 \\
Cambodia & 250 & 161 \\
Indonesia & 220 & 126 \\
Philippines & 99 & 114 \\
Vietnam & 59 & 54 \\
Malaysia & 29 & 40 \\
Thailand & 48 & 20 \\
\hline
\end{tabular}

According to the global standards for the initial education of professional nurses and midwives by World Health Organization (2012), an initial nursing or midwifery education aims to 
prepare individuals to fill a role in the professional workforce where they will be called upon to strengthen health systems to meet population needs and protect the public. High-quality education programs that meet a global standard are therefore imperative. The global standards may furthermore: 1) act as a catalyst in advocating for education change, reform and quality improvement; 2) serve as leverage in building capacity for adequate numbers of nurses and midwives and a competent workforce for strengthening health systems; and 3) serve as a basis for the development of global standards for advanced nursing and/or midwifery education. Furthermore, nursing or midwifery schools should have accessible, current and relevant physical facilities including, but not limited to, classrooms, clinical practice sites, information and communications technology, clinical simulation laboratories, and libraries. This is one of the infrastructures to develop nurses and midwives' standard that the education system should provide for nursing students.

Therefore, the education institution development was also described as having contributed to the development of midwifery education. This included the strengthening of courses and the enhancement of teaching and staffs' motivation that had led to increasing international relationships (Uys \& Middleton, 2011). The notion of university education in nursing itself still remains problematic such as there are many disparities in the programs currently being offered in different parts of the world. For instance, the length of the courses offered varies from two to five years; some countries offer nursing programs but not midwifery programs in the higher education sector; some countries offer comprehensive programs that combine nursing and midwifery while others see the two as separate professions and maintain separate education programs; some countries offer midwifery only as an option for qualified nurses, while others recognize midwifery as a profession distinct from nursing (WHO, 2012).

In Thailand, all institutions offering nursing education for four years for the bachelor of nursing science programs combines professional nursing and midwifery. All the nursing students will complete their professional nursing and midwifery license from the Thailand Nursing Council according to the professional practice of midwifery. This means that the practice of midwifery to pregnant women, post-delivery women, their newborns, and families are in the following actions: 1) to provide education, advice, counseling, as well as solving health problems; 2) to act and assist pregnant women, post-delivery women, and their newborns' physical and mental health in order to prevent complications during pregnancy, delivery, and post-delivery; 3 ) to provide treatment, as mentioned in primary medical care and immunization; 4) to provide physical examinations, delivery of the baby and family planning services; and 5) to assist physicians to perform treatment. These actions shall be based on scientific principles and the art of midwifery in performing health assessment, nursing diagnosis, planning, intervention and evaluation (Government, 1997).

The Thai midwives performances reach to the international midwives capacities perfectly. The international definition of a midwife states that: "The midwife is recognized as a responsible and accountable professional who works in partnership with women to give the necessary support, care and advice during pregnancy, labor and the postpartum period, to conduct births on the 
midwife's own responsibility, and to provide care for the newborn and the infant. This care includes preventive measures, the promotion of normal birth, the detection of complications in mother and child, the accessing of medical care or other appropriate assistance, and the carrying out of emergency measures." (International Confederation of Midwives, 2005)

Also in Thailand, compared with other countries in Asia, we include 12 credits of Maternal and Child and Midwifery courses so graduates of BNS programs can practice both nursing and midwifery. The midwifery courses are integrated into Thai nursing programs, therefore, they can be both Nurses and Midwives at the same time. These credits comprise theories and practicum to prepare the nurses for real-life scenarios. Consequently, after graduation, they can apply their knowledge to other women in remote areas orevery community in this country to support poor people.

Several key themes made Thailand successful for women's health services. Nursing education programs which combine midwifery and maternal and newborn nursing is the most important key. Emerging from the authors' reflections as Gynecology, midwifery, and maternalnewborn instructors came from experiences including educational accreditation, curriculum, student recruitment, programs, practicum, faculty role, and preceptor as presented in Table 2.

Table 2. Maternal and Newborn and Midwifery Details at Naresuan University

\begin{tabular}{|c|c|}
\hline Topics & Naresuan University \\
\hline $\begin{array}{l}\text { Nursing and Midwifery Educational } \\
\text { standard }\end{array}$ & $\begin{array}{l}\text { One Nursing and midwifery standard from Thailand Nursing } \\
\text { Council, required } 12 \text { credits of } \mathrm{MCH} \text { and midwifery }\end{array}$ \\
\hline Educational accreditation & $\begin{array}{l}\text { Accreditation from several organization such as Thailand Nursing } \\
\text { Council, The Office for Education Standards and Quality } \\
\text { Assessment (Public organization), Office of the Higher Education } \\
\text { Commission }\end{array}$ \\
\hline Curriculum & Combined Nursing and Midwifery \\
\hline Midwifery educational program & Theoretical curriculum, clinical training, and research \\
\hline Student recruitment & Students who studied from a science program in high school \\
\hline Programs & Maternal and Newborn, Women's Health Nursing, and Midwifery \\
\hline Midwifery course & $\begin{array}{l}\text { Set in relation to special areas of midwifery such as professional } \\
\text { aspects of Midwifery; Anatomy, Physiology, Pathology; basic and } \\
\text { advanced principles of maternity, and Pharmacology }\end{array}$ \\
\hline MCH and Midwifery Clinical Training & $\begin{array}{l}\text { Labor department (at least } 5 \text { cases of normal delivery practice), } \\
\text { post-partum department, ante-natal care, family planning }\end{array}$ \\
\hline Faculty's Role during training & Trainer, nurse, coach and advocator \\
\hline Faculty's Responsibility & 8 students per trainer/faculty \\
\hline Preceptor & $\begin{array}{l}25 \% \text { of courses when training the students } \\
\text {-They were trained in a preceptor program from Faculty of } \\
\text { Nursing, Naresuan University. }\end{array}$ \\
\hline Assisted technology & $\begin{array}{l}\text { Simulated pregnancies, Computer Assisted Instruction (CAI), and } \\
\text { other technologies such as website and video clips were the main } \\
\text { instruction of nursing practices }\end{array}$ \\
\hline
\end{tabular}




\section{Reflection from Experiences}

Thailand has had "a long and successful history of health development". World Health Organization (2014) addressed nurses and midwives who make up the greater part of the global health-care workforce of the successful Millennium Development Goals 5 (MDG5). They make a substantial contribution to health-delivery systems in primary care, acute care, and community care settings. In Thailand, according to the RNs competencies, the modern midwife and nurse can now assist women who may have died in the past during pregnancy and childbirth. High percentages of laboring women (97\%) are attended by skilled health personnel, much higher than the regional average (49\%). Women in Thailand are also much more likely to attend four or more antenatal visits $(74 \%)$ compared to women in other countries in Southeast Asia (43\%) and more women use contraception (81\%) compared to (58\%) (Central Intelligence Agency, 2015). The under-5 mortality rate (per 1000 live births) has decreased to 14 (2008) from 28 (2002). Infant mortality has also decreased from 20 (2002) to 16.39 deaths per 1000 live births (2011) (World Health Organization Regional Office for South-East Asia, 2014).

Training midwife and nursing students are in high demand. The supply of nursing professionals in Thailand is decreasing, the numbers remain woefully insufficient to meet the health needs and well-being of populations. There is a shortage of young people wanting to study nursing in the university level since the salary as a nurse is not at par with the workload and they want to work on their own and be less supervised. As a result, there are fewer enrollments in the nursing program at the university. Furthermore, in this time of nursing shortages and higher acuities, with evidence-based practice at the forefront of nursing, it has been shown that one-to-one labor support needs to necessitate the work of a high quality registered nurse. Thai nurses and midwives make a substantial contribution to health-delivery systems in primary care, acute care, and community care settings.

Therefore, Thailand Nursing and Midwifery Council should invest in effective clinical and research skill building, the development of tailored educational programs, and the establishment of structures and systems to enhance the midwifery workforce and ultimately, improve maternally and child health. Capacity building is critical and is up to the midwifery workforce to improve maternal and child care to support the global policy. The strategies to enhance nursing students include enhancing practice and experiences of midwifery by giving workshops, sharing expertise, knowledge and resources, outline evidence-based practice and lessons learned, sharing through simultaneous electronic discussions to name a few. As Thailand Nursing and Midwifery Council (2015) mentioned, "The midwife is recognized as a responsible and accountable professional who works in partnership with women to give the necessary support, care and advice during pregnancy, labor and the postpartum period, to conduct births on the midwife's own responsibility and to provide care for the newborn and the infant". This care includes preventive measures, the promotion of normal birth, the detection of complications in the mother and child, the accessing of medical care or other appropriate assistance, and the carrying out of emergency measures. In conclusion, training midwifery which is 
combined in a BNS curriculum is appropriate in Thailand. In addition, we should apply high technology and advanced educational interventions from developed countries to enhance nursing students' competencies who are going to be future nurses. Furthermore, midwifery and nursing in Thailand should be the center for the transfer of outstanding experiences to ASEAN nurses which could be done by inviting more students, lecturers, and administrators as part of educational exchange programs.

\section{References}

Bourgeault, I. L., Neiterman, E., \& LeBrun, J. (2011). Midwives on the move: comparing the requirement for practice and integration context for internationally educated midwives in Canada with the U.S., U. K., and Australia. Midwifery, 27, 368-375.

Brandt, S., Brooks Carthon, J., Buhler-Wilkerson, K., Connolly, C., D'Antonio, P., \& Dawley, K. (n.d.). History of Nursing Timeline. Retrieved from http://www.nursing.upenn.edu/nhhc/Pages/timeline_17001869.aspx?slider1=1

Central Intelligence Agency. (2015). The world fact book. Retrieved June 17, 2015 from https://www.cia.gov/library/publications/the-world-factbook/geos/th.html

Government, G. (1997). The professional nursing and midwifery act. B.E. 2528(1985) as amended by the Professional Nursing and Midwifery Act. B.E. 2540(1997). Retrieved from http:// www.ThaiLaws.com

Hill, K., Vapattanawong, P., Prasartkul, P., Porapakkham, Y., Lim, S.S., \& Lopez, A.D. (2007). Epidemiologic transition interrupted: a reassessment of mortality trends in Thailand, 1980-2000. International Journal of Epidemiologyl, 36:374-84. doi:10.1093/ije/ dyl257 PMID:17182635

International Confederation of Midwives. (2005). Definition of the Midwife. The Hague, The Netherlands.

Muecke, M. A., \& Srisuphan, W. (1989). Born female: The development of nursing in Thailand. Social Science \& Medicine, 29(5), 643-652.

Prakongsai, P., Tangcharoensathien, V., \& Limwattananon, S. (2008). Equity in health care finance and financial risk protection prior to and after universal coverage in Thailand. Presented at the: International Society for Pharmacoeconomics and Outcomes Research Thailand Annual Conference, Bangkok, Thailand.

Rohde, J., Cousens, S., Chopra, M., Tangcharoensathien, V., Black, R., ..., Bhutta, Z. (2008). Alma-Ata: rebirth and revision 4, 30 years after Alma-Ata: has primary health care worked in countries? Lancet, 372, 950-961. doi:10.1016/ S0140-6736(08)61405-1

Thailand Nursing Council and Midwifery. (2015). Thailand Nursing and Midwifery competencies of Registered Nurses. Retrieved from www.tnc.or.th/files/.../professional_competency_pdf_10152_ 28999.pd.

United Nations Population Fund. (2017). Midwives, mothers and families: Partners for life. Retrieved from https://www.unfpa.org/press/midwives-mothers-and-families-partners-life

Uys, L. R., \& Middleton. (2011) Internationalizing university schools of nursing in South Africa through a Community of Practice. International Nursing Review, 58, 115-122.

Vapattanawong, P., Hogan, M. C., Hanvoravongchai, P., Gakidou, E., Vos, T., ..., Lopez, A. D. (2007). Reductions in child mortality levels and inequalities in Thailand: analysis of two censuses. Lancet, 369:850-8555. doi:10.1016/S01406736(07)60413-9 
World Health Organization. (2012). Global standards for the Initial Education of Professional Nurses and Midwives. Retrieved from www.who.int/.../nursing_midwifery/hrh_glob

World Health Organization. (2014). MDG 5: Improve Maternal Health. Retrieved from http://www.who.int/topics/millennium_development_goals/maternal_health/en/

World Health Organization Regional Office for South-East Asia. (2014). Improving maternal, newborn and child health in the South-East Asia region. Retrieved from http://www.searo.who.int/en/Section260/ Section1808/Section1933.htm

\section{About the Authors}

Pratuma Rithpho, PhD, MNS, RN, has worked as a head of the Maternal and Newborn Nursing Division, Faculty of Nursing, Naresuan University (NU), Thailand. She received her bachelor's degree of nursing science (Second Class Honors) from NU. She received her Master of Nursing Science (Nursing Care of Women) and Ph.D. (International Program) from the Faculty of Nursing, Chiang Mai University, Thailand. Her master's research focused on health care behaviors among self-employed female workers and her Ph.D. dissertation focused on enhancing self-care capacity among nondisclosed people living with HIVIAIDS. In 2007, she got the Certificate of Outstanding Contribution in reviewing in recognition of the contributions she has made to the quality of the journal and a Certificate of Reviewing in recognition of the contributions made by the journal from ELSVIER in cooperation with the Association of Nurses in AIDS Care. Her field of interests include HIVIAIDS, STDs, Women's Health Nursing, Vulnerable Populations, and Midwifery.

Pantipa Buakhai, MNS, RN, was born in Thailand. She graduated with a Bachelor of Nursing Science (B.N.S) at Naresuan University in Thailand. She worked at the delivery room of Naresuan University Hospital for two years. She received a grant to study for a Master's degree from the Faculty of Nursing of Naresuan University. She graduated with a Master of Nursing Science in Midwifery (M.N.S) at Mahidol University, Thailand. Her topic thesis for her master's degree focused on violence in pregnancy. She is an instructor at the Faculty of Nursing, Naresuan University at present. Pregnancy and maternal and child health are the topics that interests her. 